\title{
Laserterapia como recurso terapêutico na fonoaudiologia
}

\author{
Laser therapy as a therapeutic resource in speech therapy \\ La terapia con láser como recurso terapéutico en logopedia
}

Recebido: 23/12/2020 | Revisado: 25/12/2020 | Aceito: 30/12/2020 | Publicado: 03/01/2021

\author{
Maria das Graças Silva Santos \\ ORCID: https://orcid.org/0000-0003-4342-0024 \\ Faculdade de Ensino Superior do Piauí, Brasil \\ E-mail: gracinhafono23@gmail.com \\ Claudia Catão de Aguiar Sousa \\ ORCID: https://orcid.org/0000-0002-6193-7484 \\ Faculdade de Ensino Superior do Piauí, Brasil \\ E-mail: klaudyakatao@hotmail.com
}

\begin{abstract}
Resumo
A utilização da terapia por meio do laser de Baixa Intensidade, caracteriza-se por sua multidisciplinariedade, pois seu uso, atualmente, ocorre por muitos profissionais de diversas áreas, como por exemplo, Fonoaudiólogos. Os profissionais da Fonoaudiologia já estão procurando utilizar esse método de terapia, em razão de ser não invasivo, ou seja, sem consequências tóxicos e colaterais, contribuindo de modo significativo nas terapias, por meio do estabelecimento de um prognóstico pautado na excelência do processo de reabilitação. O objetivo geral da presente pesquisa consiste em analisar quais as principais contribuições da laser terapia como um recurso em prol de terapia na Fonoaudiologia. Dentre os objetivos específicos ressaltam-se: definir laser terapia; identificar o papel do Fonoaudiólogo; verificar como a laser terapia pode ser utilizada pelos profissionais da Fonoaudiologia. A problemática consiste no seguinte questionamento: como a laser terapia pode auxiliar os profissionais da Fonoaudiologia em suas competências? Para fundamentar a pesquisa houve a necessidade de uma metodologia pautada em uma revisão bibliográfica ou literária analisando diversas fontes, como artigos, monografias, dissertações, livros e consultas em sites que disponibilizam trabalhos científicos, como a SCIELO e Google acadêmico, por exemplo. Infere-se que a pesquisa é pertinente, constatando-se os diversos benefícios da utilização da laser terapia pelos profissionais da Fonoaudiologia, como atuação na paralisia facial, disfagias, dentre outras.
\end{abstract}

Palavras-chave: Fonoaudiologia; Laser terapia; Reabilitação.

\begin{abstract}
The use of therapy using the Low Intensity laser is characterized by its multidisciplinary approach, since its use currently occurs by many professionals in different areas, such as speech therapists. Speech therapy professionals are already looking to use this therapy method, because it is non-invasive, that is, without toxic and collateral consequences, contributing significantly to therapies, by establishing a prognosis based on the excellence of the rehabilitation process.. The general objective of this research is to analyze what are the main contributions of laser therapy as a resource for the benefit of speech therapy. Among the specific objectives, the following stand out: to define laser therapy; identify the role of the speech therapist; to verify how laser therapy can be used by speech therapy professionals. The problem consists of the following question: how can laser therapy help speech therapy professionals in their skills? To support the research, there was a need for a methodology based on a bibliographic or literary review analyzing various sources, such as articles, monographs, dissertations, books and consultations on sites that provide scientific works, such as SCIELO and Google academic, for example. It is inferred that the research is pertinent, evidencing the various benefits of the use of laser therapy by speech therapy professionals, such as performance in facial paralysis, dysphagia, among others.
\end{abstract}

Keywords: Speech therapy; Laser therapy; Rehabilitation.

\section{Resumen}

El uso de la terapia con láser de Baja Intensidad se caracteriza por su abordaje multidisciplinar, ya que su uso se da actualmente por muchos profesionales en diferentes áreas, como los logopedas. Los profesionales de la logopedia ya buscan utilizar este método terapéutico, porque es no invasivo, es decir, sin consecuencias tóxicas y colaterales, contribuyendo de forma significativa a las terapias, al establecer un pronóstico basado en la excelencia del proceso de rehabilitación.. El objetivo general de esta investigación es analizar cuáles son los principales aportes de la terapia láser como recurso en beneficio de la logopedia. Entre los objetivos específicos destacan los siguientes: definir la terapia láser; identificar el papel del logopeda; para verificar cómo los profesionales de la terapia del habla pueden utilizar la terapia con láser. El problema consiste en la siguiente pregunta: ¿cómo puede la terapia láser ayudar a los profesionales de la logopedia en sus habilidades? Para sustentar la investigación se necesitaba una metodología basada en una revisión bibliográfica o literaria analizando diversas fuentes, como artículos, monografías, disertaciones, libros y consultas en sitios que brindan trabajos científicos, como SCIELO y Google académico, por ejemplo. Se infiere que 
la investigación es pertinente, evidenciando los diversos beneficios del uso de la terapia láser por parte de los profesionales de logopedia, como el desempeño en parálisis facial, disfagia, entre otros.

Palabras clave: Logopedia; Láser; Rehabilitación.

\section{Introdução}

A laserterapia é uma medida indicada para várias modalidades de tratamentos, de forma isolada ou associada ou como uma espécie de complemento de uma terapia que devido sua intensidade menor proporciona ao organismo do ser humano energia suficiente em prol da promoção de transformações biológicas e químicas no meio intracelular, aumentando consideravelmente a produção de Adnosina trifosfato (ATP), considerada uma molécula fundamental, no que se refere a liberação energética para as células (Pereira, 2019).

Além disso, por meio da utilização do laser terapia ocorre a promoção da ativação de enzimas consideradas antioxidantes, possibilitando, desse modo, que o organismo seja capaz de retornar o seu processo de homeostase, e consequentemente, o seu funcionamento, adequado (Trajano, 2020).

Devido a grande importância da laserterapia, a Fonoaudiologia também se utiliza dessa terapia. Por meio da utilização de laser de baixa potência, apresentando variados benefícios em várias áreas de atuação, em especial aquelas que se relacionam com a motricidade orofacial, a disfagia, o ronco, as paralisias da face, aumento potencial de treinos miofuncional em estética, contribuindo, dessa forma, em readequar a postura corporal, assim como suas funções, voz e várias outras espécies de patologias (Feraresi, 2012).

Assim, o objetivo geral da presente pesquisa consiste em analisar quais as principais contribuições, como um recurso terapêutico na Fonoaudiologia. Dentre os objetivos específicos ressaltam-se: definir; identificar o papel do fonoaudiólogo; verificar como a laser terapia pode ser utilizada pelos profissionais da Fonoaudiologia.

A problemática da pesquisa consiste no seguinte questionamento: como a laser terapia pode contribuir no auxílio aos profissionais da Fonoaudiologia em suas mais diversas competências?

Justifica-se a eleição do tema em razão da grande importância do Fonoaudiólogo em prol de tratamento de pessoas que possuem uma série de dificuldades que comprometem a vida cotidiana, como problemas na comunicação. Desse modo esses profissionais necessitam do maior número de ferramentas para um melhor desenvolvimento de seu trabalho, como por exemplo a utilização de laser em prol de várias terapias, como por exemplo no que se refere ao treino muscular, pois quando se utiliza o laser há uma potencializarão de energia, diminuindo os níveis de fadiga e, consequentemente realizando uma melhora no desempenho muscular ao executar ações como a fala.

A presente pesquisa é de suma importância, pois é mais uma teoria em prol de pesquisas de estudantes de Fonoaudiologia, assim como para profissionais que já atuam na área e necessitam um maior conhecimento sobre o papel terapeutico nas ações.

\section{Referencial Teórico}

A sigla LASER tem origem do inglês, devido a abreviação "light amplification by stimulated emissionof radiation". Sendo compreendida como fonte de luz monocromática, de forma intensa, coerente e colimada, sendo que a emissão de radiação ocorre devido o estímulo de campo externo, apresentando aplicações múltiplas e cada vez mais em ascensão na esfera industrial, na engenharia, na medicina humana e medicina veterinária (Zanotti, 2011).

O raio laser pode ser compreendido como uma modalidade de radiação eletromagnética bem peculiar, com propriedades típicas, havendo a diferenciação da luz oriunda por geradores padronizados incandescentes, sendo os tipos, 
definidos conforme algumas características, como o comprimento da onda, a sua profundidade, assim como a sua devida aplicação (Santos, 2010).

A incorporação do laser como um instrumento direcionado a terapia, não é algo recente, pois possui o acompanhamento na área da biomedicina desde o ano de 1960, por meio de Theodore Maiman. O primeiro experimento publicado no mundo, referente aos benefícios do laser de potência reduzida ocorreu, mais precisamente no ano de 1983, por meio do processo de irradiação de laser composto por Hélio e Neônio, o qual foi aplicado em ferimentos de roedores durante quatorze dias de modo ininterruptos (Henriques, 2010).

Dentre os principais benefícios da terapia associada com a utilização de laser de baixa potência há o aumento da proliferação e ativação dos linfócitos; atuação sobre os macrófagos, proporcionando o aumento significativo da fagocitose; ampliação da secreção de fatores relacionados com o aumento de fibroblasto, e consequentemente havendo a intensificação da reabsorção da fibrina e colágeno (Bashardoust, 2010).

Seja menos casos, também apresenta algumas contraindicações:

- Irradiação sobre tumores/neoplasias (benignos ou malignos);

- Fenômenos de retenção de muco (Glândulas Salivares - mucoceles, por exemplo);

- Em crianças: fontanelas/epífises de crescimento;

- Irradiação próxima a marca-passo;

- Mulheres grávidas (depende do local da aplicação).

Por essa razão de contraindicações é possível afirmar que, mesmo sendo uma técnica de utilização simples, sem causar dores nos pacientes e sem muitos efeitos colaterais, com poucas contraindicações, a sua utilização na Fonoaudiologia deve ser por meio de laser de baixa potência, sendo realizado, obrigatoriamente, por profissionais habilitados na execução desses procedimentos terapêuticos (Mouffon, 2020).

A Laserterapia, já vem há algumas décadas, trazendo uma série de revoluções no que se refere ao processo de terapia, em várias áreas da saúde, e nas mais diversas regiões do mundo, crescendo clinicamente e nas áreas científicas (Morais, 2012).

No território brasileiro houve no dia 15 de março de 2019 a publicação da resolução de número 543, a qual aborda, expressamente, sobre assuntos relacionados com a utilização do recurso de Laser de baixa intensidade-LBI pelos profissionais da Fonoaudiologia (Dogan, 2010).

Art. $\mathbf{1}^{\circ}$ Normatizar o uso do recurso de Laser de Baixa Intensidade (LBI) por fonoaudiólogos.

Art. $2^{\circ}$ No exercício de suas atividades profissionais, o fonoaudiólogo poderá utilizar o Laser de Baixa Intensidade (LBI) como recurso terapêutico associado aos procedimentos clínicos fonoaudiológicos convencionais;

Art. $3^{\circ} \mathrm{O}$ recurso terapêutico Laser de Baixa Intensidade só poderá ser utilizado para fins fonoaudiológicos, sendo o fonoaudiólogo responsável por selecionar os parâmetros dosimétricos mais adequados para cada cliente, de acordo com a necessidade clínica e modelo do equipamento utilizado.

Art. $4^{\circ}$ Na parte externa do equipamento de Laser de Baixa Intensidade (LBI), deverão constar, de forma visível e permanente:

I. a identificação do fabricante (nome ou marca);

II. a identificação do equipamento (nome e modelo comercial);

III. o número de série do equipamento;

IV. o número de registro do equipamento na Agência Nacional de Vigilância Sanitária (ANVISA).

Art. $\mathbf{5}^{\circ} \mathrm{O}$ fonoaudiólogo só poderá utilizar o recurso terapêutico quando tiver capacitação específica e adequada, estando sujeito à responsabilidade legal em casos de imperícia, negligência e imprudência.

Art. $6^{\circ}$ Considerar-se-á comprovadamente capacitado para os fins deste artigo o profissional que apresentar um dos seguintes documentos:

I. certificado de curso realizado; 
II. declaração de prática supervisionada.

Art. $7^{\circ}$ Os casos omissos serão resolvidos pelo Plenário do Conselho Federal de Fonoaudiologia.

Art. $\mathbf{8}^{\circ}$ Esta Resolução entrará em vigor na data de sua publicação no Diário Oficial da União.

A Figura 1 demonstra um profissional de Fonoaudiologia utilizando o laser de baixa frequência em uma terapia:

Figura 1 - Utilização de Laser terapia de baixa frequência na Fonoaudiologia.
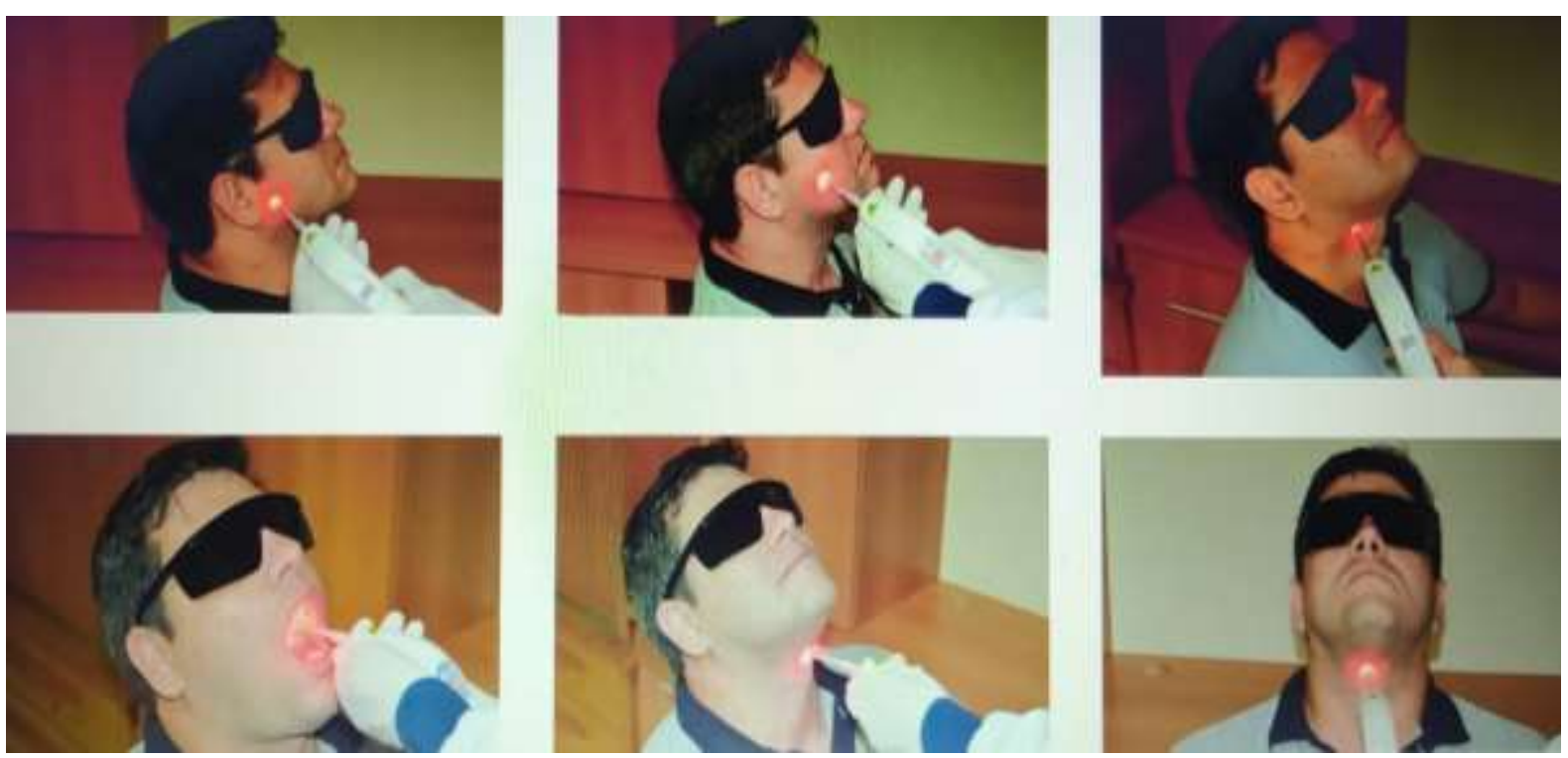

Fonte: Fonotrade (2019).

Conforme as figuras acima, é possível identificar as várias formas de utilização do laser em terapias realizadas por profissionais habilitados em Fonoaudiologia.

- A primeira figura, mostra o uso do laser em DTM, Disfunções Mandibulares, onde o laser é usado de modo não invasivo, porém de grande eficácia no tratamento das dores causadas pelos desgastes Temporomandibular.

- Na segunda imagem, mostra o uso do laser nos músculos de mimica facial, também utilizado em paralisia facial.

- Na terceira imagem, mostra o uso do laser na região laríngea, que pode ser utilizado na região infra-hióide, contribuindo no processo de deglutição, já que déficits nesses músculos podem levar à disfagia.

No que se refere aos componentes do equipamento de laser para Fonoaudiologia e suas funções básicas ressalta-se que esse procedimento conta com luz vermelha e infravermelha de baixa potência $(100 \mathrm{~mW})$, possuindo uma série de itens de segurança como, por exemplo LEDs da peça de mão, espaçadores, alarme e um feixe de mira (Trajano, 2020).

Com funções cicatrizantes, anti-inflamatórias, bactericida (PDT), analgésica e estímulo à síntese do colágeno. De forma simples, dá para dizer que a ILIB é a irradiação contínua do laser terapêutico vermelho e/ou infravermelho na região da artéria radial. As terapias por meio da utilização de laser também podem contribuir de forma significativa para a atuação de profissionais de fonoaudiologia, sendo de suma importância no que se refere, principalmente, a potencialização de terapias miofuncionais, proporcionando, assim, um ganho significativo de força, diminuindo os níveis de fadiga, além de melhorar o desempenho das funções musculares, em especial aquelas relacionadas com aspectos da fala e da linguagem (Morais, 2012).

Um método de terapia que pode ser utilizado pelos profissionais de fonoaudiologia é a ILIB (Intravascular Laser Irradiation of Blood), sendo caracterizado como um método terapêutico baseado na irradiação intravascular sanguínea, 
utilizando uma espécie de fibra óptica. Essa terapia ocorrer com a utilização de uma pulseira especifica que é colocada na região do punho. Esse método é totalmente indolor e também na apresenta nenhum tipo de queimação. A principal finalidade dessa terapia é proporcionar uma otimização e recuperação em pacientes que se encontram na fase da pós-cirurgia, reduzindo rapidamente os edemas e apresentando melhorias do estado geral do paciente hospitalizado ou que se encontram em recuperação em casa (Santos, 2010).

Associada a exercícios motores orofaciais, por meio de estudo de associação dessas duas modalidades de intervenção, com resultados que trazem equilíbrio muscular, demonstrando podendo ser uma alternativa nova de tratamento fototerápico (Cusumano, 2016).

Outra importância da laserterapia na prática Fonoaudióloga consiste na disfagia, com o laser sendo capaz de proporcionar melhorarias no fluxo da saliva, como em pacientes com xerostomia, ou seja, que apresentam ausência de saliva, assim como inibe a produção na sialorreia, quando o paciente apresenta excesso salivar (Diniz, 2012).

Outra função da associação da laserterapia com a atuação dos profissionais de fonoaudiologia consiste sempre na melhoria das várias funções relacionadas com os processos de alimentação, ressaltando-se principalmente de mastigação, na palatalização, possibilitando, o retorno de forma mais célere à via oral (Morais, 2012).

No que se refere às modalidades de terapia indireta, a terapia por meio da utilização de laser aplica-se com o objetivo principal de proporcionar um maior estímulo do trofismo dos músculos que, quando associada com exercícios miofuncionais, é capaz de favorecer a tonificação ou o relaxamento dos músculos (Santos, 2010).

Mouffron (2020) discorre sobre os principais benefícios da laserterapia na atuação dos profissionais de Fonoaudiologia:

Seus benefícios no treino muscular potencializam a terapia miofuncional e a mioterapia, acelerando o ganho de força, reduzindo os níveis de fadiga e melhorando o desempenho dos músculos durante a execução de diversas funções. Dessa forma, torna-se um ótimo recurso para ser explorado nas áreas de motricidade orofacial, estética, ronco, disfagia, e também na assistência em voz clínica e/ou profissional.

Na disfagia, no entanto, seu uso vai muito além do treino muscular! O laser é bastante utilizado para a modulação do fluxo salivar, tanto em pacientes com xerostomia que se beneficiam da normalização da saliva quanto em casos neurológicos nos quais o objetivo é a redução do volume de saliva.

Além disso, por ser um excelente aliado nas patologias que envolvem alterações do sistema nervoso, sobretudo periférico, contribui para melhora da sensibilidade intraoral em pacientes com atraso no disparo do ato motor da deglutição. O contrário também é possível, sendo utilizado para inibição em casos de hipersensibilidade, como nos reflexos patológicos, que muitas vezes atrapalham a estimulação fonoaudiológica, a introdução de utensílios ou a higienização oral, por exemplo. Outras aplicações mais difundidas, como nas paralisias faciais, parestesias e dores neuropáticas também são um grande campo para utilização da laserterapia em Fonoaudiologia.

Além disso, a laserterapia também contribui, de forma significativa, para suavização das rugas presentes na face do ser humano e apaziguando as marcas de expressão, pois a partir do momento em que ocorre estimulação na produção de colágenos evidenciam-se melhorias em aspectos relacionados com a hidratação da pele e com a microcirculação local.

Já a fotobiomodulação é uma modalidade de terapia luminosa que utiliza formas não ionizantes de fontes de luz, incluindo LASER, LEDs e/ou luzes de banda larga, no espectro visível e infravermelho. É um processo não térmico que provoca eventos fotofísicos e fotoquímicos em várias escalas biológicas. Trata-se de uma técnica não invasiva, indolor, com baixo risco para o paciente e sem efeitos colaterais. O principal mecanismo de ação desse recurso consiste no chamado efeito fotoquímico. A energia luminosa é absorvida por organelas denominadas cromóforos, presentes, especialmente, nas mitocôndrias, e transformada em energia química durante o processo de respiração celular. Por meio de reações enzimáticas, o laser estimula o aumento da síntese de adenosina trifosfato (ATP), substância essencial para o adequado funcionamento das células (Garcez, 2012). 
A fotobiomodulação possuía a capacidade de promover transformações na atividade elétrica e, consequentemente, no que se relacionada com o desempenho do músculo orbicular bucal. A fotobiomodulação interfere diretamente em mecanismos bioquímicos de contração, e a sua ação nas mitocôndrias possui uma influência bastante singnificativa sobre exercícios de resistência. Acredita-se que os resultados positivos para pressão máxima do lábio e das diferenças encontradas na atividade elétrica do músculo demonstrem que a irradiação com o LASER de baixa intensidade é capaz de influenciar, diretamente, na atividade da musculatura (Ferraresi, 2012).

Ainda é possível afirmar que a fotobiomodulação é capaz proporcionar melhorias em pessoas com zumbido crônico. Por meio dessa terapia evidencia-se a diminuição desse problema já nas primeiras sessões sendo que aqueles que recebem a fotobiomodulação apresentam melhoras no nível de insatisfação com o zumbido, independentemente do momento de avaliação e do número da sessão (Silva, 2019).

A terapia miofuncional orofacial instituída posteriormente a analgesia com LBI é capaz de promover o devido equilíbrio das funções orofaciais da amostra estudada e diminuição dos sinais e sintomas de DTM remanescentes, de acordo com a autopercepção de indivíduos que receberam esse tipo de tratamento fonoaudiológico por meio de laserterapia (Melchior, et al 2016).

Contribui com respostas céleres e efetivas para diversos problemas da saúde humana, como analgesias, inflamações, reparações do tecido e na performance dos músculos contribui também para o tratamento de profissionais, como músicos e professores que necessitam da voz (Ortiz, 2019).

A laserterapia também pode ser benéfica em aspectos referentes a apneia e o ronco. Diferentes métodos de tratamento do ronco e da SAOS auxiliam as pessoas na redução dos quadros de apneia, melhorando significativamente a qualidade do sono e de vida em geral do indivíduo. Como exemplos de métodos de reabilitação é possível citar os dispositivos intra-orais, também tem como alternativa em casos de ronco primário ou em apneia leve, o CPAP (Continuous Positive Airway Pressure), dispositivo que previne o fechamento e estreitamento das vias aéreas durante o sono, entre outros. Além disso, o tratamento cirúrgico da SAOS também é uma opção, na qual se inclui a uvulopalatofaringoplastia, a glossectomia a laser, osteotomia mandibular inferior, entre outras técnicas, no entanto, a opção cirúrgica é considerada bastante invasiva, e pode gerar sequelas como a disfagia e alterações na ressonância da fala (Oliveira, 2018).

\section{Metodologia}

A metodologia da pesquisa pode ser considerada com uma revisão bibliográfica do tipo integrativa, alicerçada por meio da análise de diversas teorias científicas, referente aos principais benefícios da Laserterapia na qualidade de mais um recurso terapêutico na Fonoaudiologia. Para lograr êxito na pesquisa recorreu-se a sites especializados destinados a disponibilização de pesquisas científica, como por exemplo, o Google acadêmico e Scielo, PubMed, dentre outros, utilizando na busca os seguintes descritores: laserterapia e Fonoaudiologia.

A abordagem realizada é de natureza qualitativa que tenta compreender certos "fenômenos" comportamentais através da coleta de dados narrativos e estudando as preferências individuais de cada um (Perreira A.S. et al (2018).

Foram selecionadas na presente pesquisa somente fontes de pesquisa produzidas no lapso temporal compreendido entre o ano de 2015 e o ano de 2020 procurando, desse modo, espera-se proporcionar uma maior atualidade dessa revisão. Foram utilizadas também fontes de pesquisa escritas em língua portuguesa, inglesa e espanhola. No entanto só foram admitidas na pesquisa fontes que se encontram traduzidas para a língua portuguesa, sendo excluídas as fontes de pesquisa que se encontram escritas em outros idiomas. A escolha das fontes de pesquisa ainda se basearam na análise dos resumos dos estudos pesquisados, sendo incluídas somente aquelas fontes que procuravam abordar os benefícios, mais relacionada com as atividades realizadas pelos profissionais de Fonoaudiologia (Perreira A.S. et al (2018). 
Considerando como método a revisão sistemática e considerando os descritores já mencionados, foram encontrados 21 artigos nas bases de dados SCIELO (Scientific Eletronic Library On line), LILACS (Literatura Latino Americana e do Caribe em Ciências da Saúde) e PubMed. Os artigos apresentados em mais de uma base de dados foram contabilizados apenas uma vez (Figura 2).

Figura 2 - Quantidade de artigos conforme a base de dados.

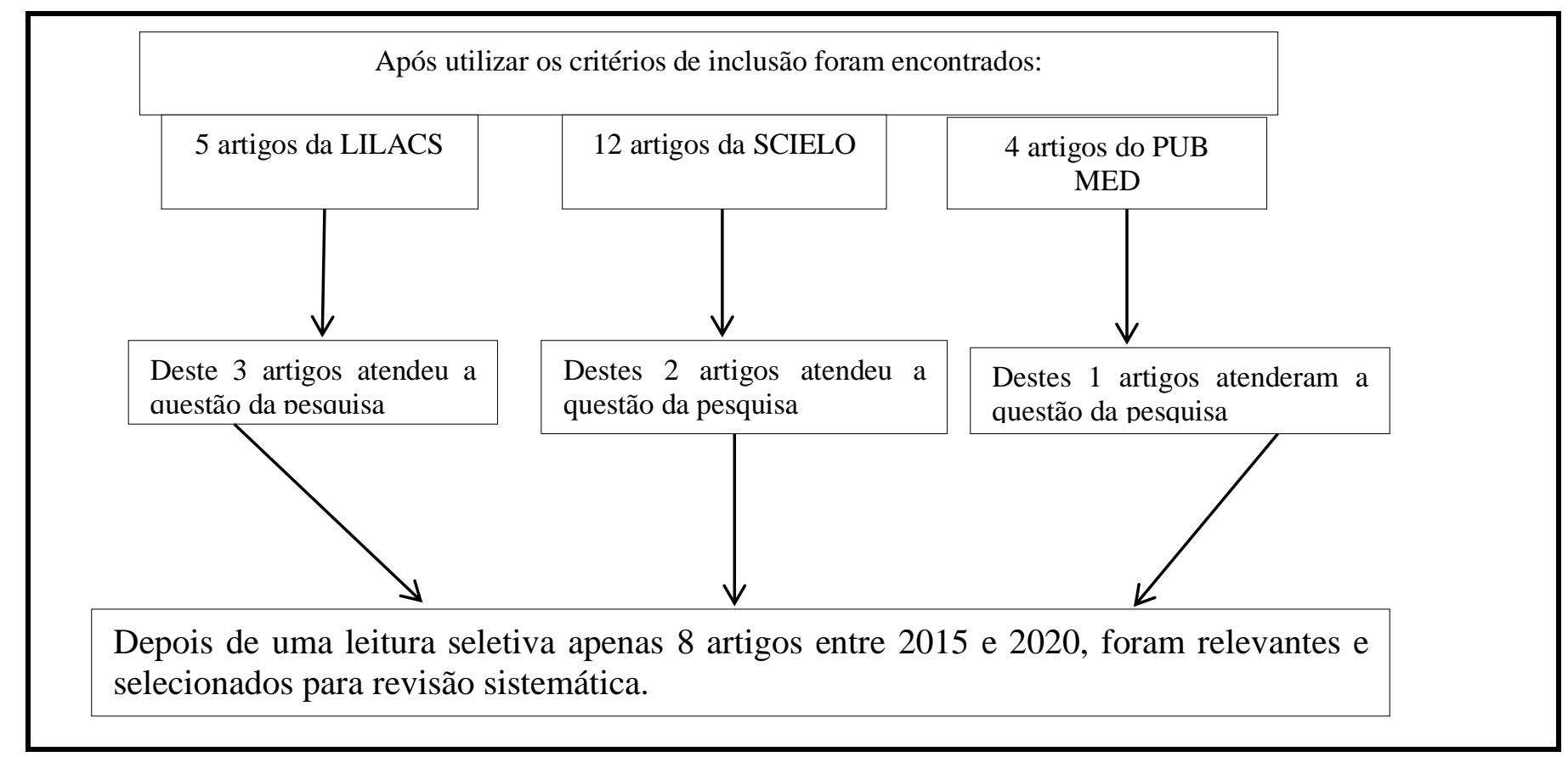

Fonte: Autores (2020).

Posteriormente a seleção dos artigos utilizados na presente pesquisa houve a necessidade da elaboração de um quadro no qual são inseridos o autor, o local de publicação, o tipo de metodologia e os resultados presentes nas fontes consultadas.

Quadro 2 - Análise da importância da laserterapia como um recurso da Fonoaudiologia

\begin{tabular}{|c|c|c|c|}
\hline $\begin{array}{l}\text { Autor } \\
\text { Título }\end{array}$ & Revista & Metodologia & Resultados \\
\hline $\begin{array}{l}\text { Melchior et.al } 2016 \\
\text { Efeito do tratamento } \\
\text { fonoaudiológico após } \\
\text { a laserterapia de } \\
\text { baixa intensidade em } \\
\text { pacientes com DTM: } \\
\text { estudo descritivo }\end{array}$ & SCIELO & $\begin{array}{l}\text { Transcorridos } 30 \text { dias após a finalização da } \\
\text { LBI, cinco pacientes foram avaliados, com } \\
\text { idades entre } 50 \text { e } 61 \text { anos. A aplicação do } \\
\text { questionário ProDTMMulti para investigação } \\
\text { da autopercepção da sintomatologia de DTM e } \\
\text { do exame clínico AMIOFE (Avaliação } \\
\text { Miofuncional Orofacial com Escores) para } \\
\text { constatação das condições miofuncionais } \\
\text { orofaciais foram realizados por fonoaudióloga } \\
\text { experiente, antes e após a TMO. }\end{array}$ & $\begin{array}{l}\text { As CMO apresentaram aumento dos } \\
\text { escores após TMO, indicando } \\
\text { aumento do equilíbrio miofuncional } \\
\text { orofacial. De acordo com a percepção } \\
\text { das pacientes, após a TMO houve } \\
\text { alívio dos sinais e sintomas de DTM. }\end{array}$ \\
\hline
\end{tabular}




\begin{tabular}{|c|c|c|c|}
\hline $\begin{array}{l}\text { Efeito de exercícios } \\
\text { motores orofaciais e } \\
\text { laserterapia nos } \\
\text { sintomas de } \\
\text { desordem } \\
\text { temporomandibula } \\
\text { e funções orofaciais }\end{array}$ & PUBMED & $\begin{array}{l}\text { Participaram } 104 \text { pacientes com DTM, } \\
\text { examinados segundo o Research Diagnostic } \\
\text { Criteria for Temporomandibular Disorders } \\
\text { RDC/DTM e classificados de acordo com o } \\
\text { tipo de DTM seguindo o Diagnostic Criteria } \\
\text { for Temporomandibular Disorder (DC/TMD). } \\
\text { Participaram ainda } 20 \text { sujeitos sem DTM, } \\
\text { equilibrados por gênero e idade com os grupos } \\
\text { experimentais. Os pacientes com DTM foram } \\
\text { divididos aleatoriamente em quatro grupos de } \\
\text { tratamento com } 26 \text { participantes cada: Grupo } \\
\text { II, no qual a TMO foi realizada de acordo com } \\
\text { protocolo previamente publicado (Felício, } \\
\text { 2009; Felício et al., 2010; Felício e Machado, } \\
\text { 2012), composto por técnicas de alivio da dor } \\
\text { e exercícios motores orofaciais e recuperação } \\
\text { das funções; Grupo III que recebeu LLLT } \\
\text { combinada com EMO, sendo a sessão iniciada } \\
\text { com aplicação do laser de Arseneto de Gálio e } \\
\text { Alumínio (AsGaAl) com uma dose de } 60 \\
\text { J/cm², na região da ATM e sobre os locais } \\
\text { doloridos na musculatura seguida dos EMO; } \\
\text { Grupo IV que recebeu LLLT placebo } \\
\text { associada a EMO, sendo os mesmos } \\
\text { procedimentos do GIII, porém a aplicação do } \\
\text { laser foi realizada com a ponta inativa; e } \\
\text { Grupo V que recebeu laser de baixa } \\
\text { intensidade exclusiva. }\end{array}$ & $\begin{array}{l}\text { As modalidades com alguma } \\
\text { estratégia de alívio da dor (LLLT ou } \\
\text { relaxamento e massagens) e EMO } \\
\text { combinados (GII e GIII) foram mais } \\
\text { efetivas para a redução de sintomas } \\
\text { de DTM, sensibilidade à palpação e } \\
\text { dificuldade para mastigar, bem como } \\
\text { para o aumento do limiar de dor à } \\
\text { pressão e a recuperação das funções } \\
\text { orofaciais. O GIII apresentou maior } \\
\text { equilíbrio entre os músculos } \\
\text { temporais e masseteres refletidos pelo } \\
\text { índice ATTIV. Entre os outros dois } \\
\text { grupos, o GIV (LLLT } \\
\text { placebo+EMO) resultou em melhores } \\
\text { condições miofuncionais orofaciais e } \\
\text { maior redução de dificuldade para } \\
\text { mastigar, enquanto o GV (LLLT) } \\
\text { produziu maior decréscimo dos } \\
\text { sintomas de DTM. A magnitude do } \\
\text { efeito do tratamento para } \\
\text { sensibilidade à palpação e limiar de } \\
\text { dor à pressão foi similar entre estes } \\
\text { dois grupos. }\end{array}$ \\
\hline $\begin{array}{c}\text { O uso do laser de } \\
\text { baixa intensidade em } \\
\text { indivíduos com } \\
\text { zumbido e sem perda } \\
\text { auditiva }\end{array}$ & $\overline{C S}$ & $\begin{array}{l}\text { O estudo foi desenvolvido no Centro Auditivo } \\
\text { Ouvir Bauru, com a aprovação do Comitê de } \\
\text { Ética em Pesquisa e aquiescência do paciente } \\
\text { confirmada mediante a assinatura do Termo } \\
\text { de Consentimento Livre e Esclarecido. Os } \\
\text { pacientes que se enquadravam nos critérios de } \\
\text { inclusão foram divididos aleatoriamente em } \\
\text { Grupo 1: uso do laser de baixa intensidade e } \\
\text { Grupo 2: uso do placebo. Foi realizado } \\
\text { anamnese com os indivíduos antes da } \\
\text { realização da bateria de testes e os dados } \\
\text { coletados foram anotados no prontuário do } \\
\text { mesmo. Após entrevista, iniciou-se a bateria } \\
\text { de exames audiológicos que incluiu: } \\
\text { audiometria tonal, audiometria de altas } \\
\text { frequências, imitanciometria e acufenometria } \\
\text { para descarte de perda auditiva, questionário } \\
\text { Tinnitus Handicap Inventory para mensurar o } \\
\text { nível de incomodo com o zumbido pré e pós } \\
\text { tratamento e escala visual analógica para } \\
\text { mensurar o nível de incômodo pré e pós } \\
\text { aplicação do laser. O protocolo de } \\
\text { fotobiomodulação incluiu } 12 \text { sessões de laser } \\
\text { de baixa intensidade para o Grupo } 1 \text { e placebo }\end{array}$ & $\begin{array}{l}\text { a amostra foi composta por } 20 \\
\text { pacientes, sendo oito do sexo } \\
\text { feminino e } 12 \text { do sexo masculino com } \\
\text { média de idade de } 54 \text { anos. Não } \\
\text { houve diferença estatística em função } \\
\text { do grupo de intervenção e do } \\
\text { momento de avaliação para os } \\
\text { desfechos audiometria de altas } \\
\text { frequências e acufenometria. A } \\
\text { desvantagem dos indivíduos com } \\
\text { zumbido crônico reduziu } \\
\text { significativamente após a } \\
\text { intervenção, independentemente da } \\
\text { intervenção. Pode-se averiguar que a } \\
\text { insatisfação dos indivíduos com } \\
\text { zumbido crônico diminuiu } \\
\text { significativamente com diferença } \\
\text { entre as sessões iniciais e finais, } \\
\text { independentemente do grupo de } \\
\text { intervenção, porém, o Grupo } 1 \\
\text { apresentou redução } \\
\text { significativamente maior que o Grupo } \\
\text { 2, independentemente do momento }\end{array}$ \\
\hline
\end{tabular}




\begin{tabular}{|c|c|c|c|}
\hline & & $\begin{array}{l}\text { para o Grupo } 2 \text {, utilizando } 4 \mathrm{~J} \text { na veia lingual } \\
\text { no comprimento de onda vermelho, } 4 \mathrm{~J} \text { na } \\
\text { membrana timpânica direita e esquerda, no } \\
\text { comprimento de onda vermelho e } 9 \mathrm{~J} \text { na } \\
\text { mastoide direita e esquerda, no comprimento } \\
\text { de onda infra-vermelho. }\end{array}$ & de avaliação e do número da sessão \\
\hline Ferreira, 2020 & SCIELO & $\begin{array}{l}\text { estudo transversal, analítico, randomizado e } \\
\text { triplo-cego, onde os indivíduos foram } \\
\text { divididos em quatro grupos, sendo P1 (grupo } \\
\text { placebo com aplicação de trinta segundos por } \\
\text { ponto), P2 (grupo placebo com aplicação de } \\
\text { sessenta segundos por ponto), E1 (grupo ativo } \\
\text { com aplicação de } 3 \mathrm{~J} / \text { ponto) e E2 (grupo ativo } \\
\text { com aplicação de } 6 \mathrm{~J} / \text { ponto). Foram realizadas } \\
\text { as seguintes avaliações nos músculos } \\
\text { masseteres, pré e pós intervenção: } \\
\text { termografia, avaliação objetiva do tônus } \\
\text { muscular, avaliação da espessura muscular, } \\
\text { força de mordida e avaliação da atividade } \\
\text { elétrica muscular. }\end{array}$ & $\begin{array}{l}\text { Para os grupos placebo, as variáveis } \\
\text { espessura à direita e esquerda, } \\
\text { elasticidade à direita, tônus à } \\
\text { esquerda e atividade elétrica à } \\
\text { esquerda durante mastigação à direita } \\
\text { sofreram modificações. A espessura e } \\
\text { a elasticidade aumentaram após a } \\
\text { aplicação da laserterapia placebo e o } \\
\text { tônus e a atividade elétrica } \\
\text { diminuíram. No grupo experimental } \\
\text { E1, que utilizou 3J/ponto houve } \\
\text { aumento significativo da espessura à } \\
\text { esquerda durante contração, da } \\
\text { rigidez à direita e diminuição do } \\
\text { tônus à esquerda. Já no grupo E2, } \\
\text { nenhuma das variáveis apresentou } \\
\text { modificação significativa. As } \\
\text { variáveis que apresentaram alterações } \\
\text { têm relação com parâmetros de } \\
\text { fadiga muscular. Acredita-se que a } \\
\text { quantidade de } 6 \mathrm{~J} \text { de Energia } \\
\text { proporcionou ao músculo masseter } \\
\text { uma maior resistência à fadiga e às } \\
\text { demais alterações consequentes da } \\
\text { contração muscular repetitiva. }\end{array}$ \\
\hline $\begin{array}{c}\text { Laserterapia no } \\
\text { controle da disfunção } \\
\text { temporomandibular } \\
\text { dolorosa: evidências } \\
\text { científicas }\end{array}$ & LILACS & $\begin{array}{l}\text { O número de participantes dos estudos variou } \\
\text { de dezoito a sessenta e quatro indivíduos e, } \\
\text { dentre os cinco estudos analisados, três foram } \\
\text { realizados no Brasil. Dois estudos tiveram } \\
\text { mais de um grupo experimental com } \\
\text { dosimetrias diferentes na aplicação do laser e } \\
\text { apenas um artigo apresentou outra terapia } \\
\text { associada. Em relação ao diagnóstico da } \\
\text { DTM, três artigos utilizaram o RDC/TMD } \\
\text { como o instrumento de avaliação. O número } \\
\text { total de sessões variou de três a dez, com } \\
\text { periodicidade semanal de duas a quatro vezes } \\
\text { na semana, cuja duração do tratamento variou } \\
\text { de uma a cinco semanas. O aparelho e a } \\
\text { dosimetria dos estudos foram diferentes, } \\
\text { porém a maioria dos estudos apresentou o } \\
\text { modo de emissão do laser contínuo e apenas } \\
\text { um artigo não apresenta essa informação. O } \\
\text { tempo de aplicação no grupo experimental e } \\
\text { no grupo placebo variou de dez a sessenta }\end{array}$ & $\begin{array}{l}\text { Foi possível identificar que dos cinco } \\
\text { estudos selecionados, quatro } \\
\text { apresentaram resultados de melhora } \\
\text { nos sintomas dolorosos com o uso da } \\
\text { laserterapia e um demonstrou } \\
\text { resultados semelhantes ao grupo } \\
\text { placebo. Todavia, devido ao número } \\
\text { limitado de estudos e variabilidades } \\
\text { na forma de avaliação e apresentação } \\
\text { dos resultados, não foi possível } \\
\text { aplicar o tratamento estatístico } \\
\text { (metanálise) para comprovar a } \\
\text { efetividade da laserterapia. }\end{array}$ \\
\hline
\end{tabular}




\begin{tabular}{|c|c|c|c|}
\hline & & $\begin{array}{l}\text { segundos. Dos cinco artigos, quatro utilizaram } \\
\text { o tipo de laser GaAlAs e um utilizou GaAs }\end{array}$ & \\
\hline $\begin{array}{l}\text { Terapia miofuncional } \\
\text { na reabilitação do } \\
\text { ronco e apneia: } \\
\text { revisão integrativa }\end{array}$ & LILACS & $\begin{array}{l}\text { Trata-se de uma revisão integrativa sobre o } \\
\text { tema "Terapia Miofuncional na reabilitação do } \\
\text { Ronco e Apneia", com busca de } \\
\text { referências por meio da exploração de bancos } \\
\text { de dados do Portal de Pesquisa da BVS, } \\
\text { utilizando os seguintes } \\
\text { descritores e suas combinações: "Ronco" } \\
\text { "Apneia Obstrutiva do Sono" e "Terapia } \\
\text { Miofuncional". Foram inclusos } \\
\text { artigos dos últimos } 10 \text { anos, nacionais e } \\
\text { internacionais, que possuam texto completo, } \\
\text { na língua portuguesa, que se } \\
\text { relacionavam com o tema da pesquisa }\end{array}$ & $\begin{array}{l}\text { Os artigos selecionados na revisão } \\
\text { abordavam a aplicação da terapia } \\
\text { Miofuncional por meio da } \\
\text { laserterapia em casos de ronco e } \\
\text { apneia, tanto em crianças, quanto em } \\
\text { adultos e associados ou não com } \\
\text { outras técnicas } \\
\text { terapêuticas. Eles demonstraram que } \\
\text { os exercícios miofuncionais são } \\
\text { eficazes e apresentam resultados } \\
\text { satisfatórios para } \\
\text { redução do ronco noturno e diurno, } \\
\text { afilamento de língua e melhora do } \\
\text { tônus de palato e úvula }\end{array}$ \\
\hline
\end{tabular}

Fonte: Autores (2020).

\section{Resultados Discussão}

Conforme a pesquisa, foi possível identificar, por meio revisão sistemática, que a laserterapia na Fonoaudiologia e Motricidade Orofacial instituída após a analgesia com laser de baixa intensidade, promoveu equilíbrio das funções orofaciais e diminuição dos sinais e sintomas de DTM remanescentes, de acordo com a autopercepção dos indivíduos tratados. Acredita-se que a indicação de condutas clínicas que visem à analgesia previamente à TMO também corrobore com resultados semelhantes (Melchior et. al. 2016).

Evidenciou-se que a laseterapia é bastante efetivas para a redução de sintomas de DTM, sensibilidade à palpação e dificuldade para mastigar, bem como para o aumento do limiar de dor à pressão e a recuperação das funções orofaciais (Cusumano, 2016).

Infere-se que os dois autores supracitado demonstram que a utilização da laserterpaia na Fonoaudiologia pode contribuir significativamente para a redução de dores, e consequentemente haverá alívio dos principais sinais e dos sintomas de DTM.

Também é bastante benéfica no que se refere a questões relacionadas com a apneia e o ronco, tanto em crianças, quanto em adultos e associados ou não com outras técnicas terapêuticas. Eles demonstraram que os exercícios miofuncionais são eficazes e apresentam resultados satisfatórios para redução do ronco noturno e diurno, afilamento de língua e melhora do tônus de palato e úvula (oliveira, 2018).

Os autores investigados compreendem que a utilização da laserterapia como recursos fonoaudiológicos são capazes de proporcionar uma série de benefícios, contribuindo até mesmo para a diminuição de práticas como o ronco por exemplo, melhorando também a questão do afilamento de língua e também de melhoras significativas na melhora do tônus de palato e úvula

Constatou-se por meio da presente pesquisa um número reduzido de trabalhos científicos relacionado com os benefícios da laserterapia na Fonoaudiologia, sendo utilizadas, assim, somente 6 estudos referente a temática. 


\section{Considerações Finais}

Constatou-se na presente pesquisa os vários benefícios, como um recurso de suma importância na atuação dos profissionais de Fonoaudiologia.

Dentre os benefícios da terapia por meio de laser na atuação dos profissionais de Fonoaudiologia encontram-se um ganho significativo de força, reduzindo consideravelmente os níveis de fadiga, melhorarias no desempenho das funções musculares, relacionadas com aspectos da fala e da linguagem; disfagia, por meio de melhorarias no fluxo da saliva; melhorias nas funções de mastigação, na palatalização; estímulo do trofismo da musculatura; tonificação ou o relaxamento muscular;

Modulação da inflamação no tratamento da Paralisia Facial; estímulo e regeneração do nervo lesionado; suavização de rugas e marcas de expressão; Melhoria da microcirculação local e da hidratação da pele; Recuperação em pós-cirúrgicos, proporcionando redução mais rápida dos edemas.

Por meio da pesquisa foi possível identificar a grande importância do laser terapia nas ações fonoaudiológica, no entanto constatou-se a pouca produção literária referente a essa temática, necessitando que sejam realizadas mais pesquisas, em especial, estudos práticos, em prol de compreender de forma prática sobre e atuação do laser terapia. A pesquisa é pertinente, podendo ser utilizada como mais uma fonte de pesquisa sobre a associação entre a terapia utilizando laser e a atuação dos profissionais de fonoaudiologia.

Sugere- se, que sejam realizadas pesquisas, de forma continua, sobre a utilização da Laserterapia na Fonoaudiologia, em razão de bons resultados, encontrados nas mediantes pesquisas. Expandindo ainda mais a importância de atuação profissional, nesta área.

\section{Referências}

Bashardoust, T. (2010). Efeitos da irradiação de laser de baixa potência na cicatrização óssea em animais: uma meta-análise. J Orthop Surg Res.

Busnardo, V. L. (2010). Os efeitos do laser hélio-neônio de baixa intensidade na cicatrização de lesões cutâneas induzidas em ratos. Rev bras fisioter.

Conselho Federal de Fonoaudiologia. (2020). Exercício profissional do fonoaudiólogo. http://www.crefono4.org.br.

Cusumano, B. C. Z. (2016). Efeito de exercícios motores orofaciais e laserterapia nos sintomas de desordem temporomandibular e funções orofaciais. [Tese]. Ribeirão Preto (SP): Faculdade de Medicina de Ribeirão Preto da Universidade de São Paulo;

Diniz, R. D. (2011). Demanda em fonoaudiologia em um serviço público municipal da região Sul do Brasil. Rer. Soc. Bras. Fonoaudiologia.

Dogan S. K. (2010). A eficácia da laserterapia de baixo nível na síndrome do impacto subacromial: um estudo prospectivo duplo-cego controlado por placebo randomizado. Clinics.

Ferraresi, C. (2012). Low-level laser (light) therapy (LLLT) on muscle tissue: performance, fatigue and repair benefited by the power of light. Photon Lasers Med.

Ferreira, S. L. S. (2020). Efeito da laserterapia na performance do músculo masseter. Dissertação (Mestrado em Saúde da Comunicação Humana) Universidade Federal de Pernambuco, Recife.

Garcez, A. S. (2012). Terapia Laser de baixa potência nas desordens temporomandibulares. In: Garcez AS, Ribeiro MS, Núnez SC, editores. Laser de baixa potência: princípios básicos e aplicações clínicas na Odontologia. Rio de Janeiro: Elsevier.

Henriquez, A. C. G. (2010). Ação da laserterapia no processo de proliferação celular: revisão de literatura. Rev ColBras Cir.

Morais, A. A. (2012). Tinnitus in individuals without hearing loss and its relationship with temporomandibular dysfunction. Brazilian journal of otorhinolaryngology, associação brasileira de otorrinolaringologia e cirurgia cérvico-facial, São Paulo, 78(2), 59-65.

Ortiz, M. (2020). Laserterapia Aplicado na Fonoaudiologia. marciaortiz.com.br.

Melchior, M. O. (2016). Efeito do tratamento fonoaudiológico após a laserterapia de baixa intensidade em pacientes com DTM: estudo descritivo. CoDAS, $28(6)$.

Moufron, V. (2020). Entenda como o laser de baixa potência pode ser aplicado à fonoaudiologia. VMFONO. http://www.vmfono.com.br/2017/08/29/laser-debaixa-potencia/

Oliveira, A. A. (2018). Terapia miofuncional na reabilitação do ronco e apneia: revisão integrativa. Revista Thêma et Scientia. 8(1). 
Research, Society and Development, v. 10, n. 1, e8310111463, 2021

(CC BY 4.0) | ISSN 2525-3409 | DOI: http://dx.doi.org/10.33448/rsd-v10i1.11463

Pereira, A. S. M. (2019). Laserterapia no controle da disfunção temporomandibular dolorosa: evidências científicas. https://doi.org/10.11606/D.25.2019.tde27082019-182553, Bauru.

Ruivo, N. G. V. (2014). Saúde auditiva e integralidade no cuidado: Itinerário de usuários na rede de serviços [Mestrado]. Campinas: Universidade Estadual de Campinas; 2014.

Santos T. S. (2010). Eficácia da laserterapia na disfunção temporomandibular: estudo de controle. Braz J Otorhinolaryngol.

Silva, M. R. (2019). O uso do laser de baixa intensidade em indivíduos com zumbido e sem perda auditiva. Catálogo da USP. Faculdade de Odontologia de Bauru.

Trajano, R. (2020). Equipamento de Laser para Fonoaudiologia. Instituto Ricardo Trajano. https://www.ricardotrajano.com.br/equipamento-laserfonoaudiologia. 